\title{
Redefining maladaptation
}

Sirkku Juhola, Erik Glaas, Björn-Ola Linnér and Tina Simone Neset

The self-archived postprint version of this journal article is available at Linköping University Institutional Repository (DiVA):

http://urn.kb.se/resolve?urn=urn:nbn:se:liu:diva-124351

N.B.: When citing this work, cite the original publication.

Juhola, S., Glaas, E., Linnér, B., Neset, T. S., (2016), Redefining maladaptation, Environmental

Science and Policy, 55(1), 135-140. https://doi.org/10.1016/j.envsci.2015.09.014

Original publication available at:

https://doi.org/10.1016/j.envsci.2015.09.014

Copyright: Elsevier

http://www.elsevier.com/

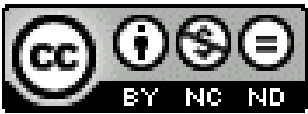




\title{
Reconceptualising maladaptation
}

\begin{abstract}
As experiences of implementation of climate change adaptation are accumulating, there is a need to increase the understanding of negative effects that might occur and the capacity to assess them. Maladaptation in this context has remained elusively defined and sparingly used, and therefore difficult to apply. Based on a literature review, we identify the conceptual boundaries of maladaptation, assess how it can be used to analyse negative effects of adaptation policies and measures and propose a typology of maladaptation. We argue that maladaptation can be defined as $a$ result of an intentional adaptation policy or measure leading to negative outcome(s) for the targeted or other actors. We note that the recognition of adaptation as an intentional action and the importance of setting clear spatial and temporal boundaries in analysing negative outcomes is key. The proposed typology of maladaptation distinguishes between three types of maladaptive outcomes - rebounding vulnerability, shifting vulnerability and eroding sustainable development.
\end{abstract}




\section{Impacts of adaptation policy}

As the need for adaptation to climate change has been widely recognised (Pielke et al. 2007, IPCC 2007, IPCC 2014), the study of adaptation as a social process has generated a field of research that is rapidly accumulating (Smit et al. 2000; Kelly and Adger 2000; Adger et al. 2005; Smit and Wandel 2006; Gallopín 2006; Füssel 2007a; Füssel 2007b; Ford et al. 2010). In broad terms, this development can be characterised with a move from impact led research towards a better understanding of social processes that underlie the ability of societies to adapt to the consenquences brought about by climate change (Burton et al. 2002; Biesbroek et al. 2010).

Progress has also been made in terms of practical steps taken to adapt with most countries now having begun to produce adaptation plans. The literature on the outcomes of adaptation has primarily asked how successful adaptation actions have been in relation equity, efficiency and legitimacy (Adger et al. 2007). It has also centred on different kinds of comparisons of national or local approaches and more recently on the identification of barriers and limits to adaptation (Adger et al. 2009; Moser and Ekstrom 2010; Biesbroek et al. 2013).

However, the literature has so far been focused on the effects and management of weather related impacts on human and natural systems, while putting less effort into studying the effects of implemented adaptation policy and measures (Klein and Juhola 2014). As experiences of implementing adaptation are accumulating at a rapid pace, there is a need to increase the understanding of negative side effects of adaption actions.

The concept maladaptation has been proposed to study outcomes of adaptation that fail to reduce climate related risk, or that lead to excessive costs. The earlierst attempts to systematically pin down what maladaptation means emerged from Barnett and O’Neill (Barnett and O'Neill 2010) and others have followed since (Richards and Howden 2012:246). Recognising the early mentions of the concept by Smit (1997) and Burton (1997) in the 1990s, Barnett and O'Neill define malaptation to be 'action taken ostensibly to avoid or reduce vulnerability to climate change that impacts adversely on, or increases the vulnerability of other systems, sectors or social groups' (Barnett and O'Neill 2010: 211). The authors furhter point to five different types of maladaptation that can arise, namely in the form of increasing emissions, vulnerability or opportunity costs and reducing incentives or limiting choices for future generations.

Despite these conceptual efforts and the unspoken recognition that not all adaptation actions will be successful, the concept of maladaptation has remained sparingly used and elusive, which has made it difficult to apply as an analytical concept for studying outcomes of adaptation policy (Noble et al 
2014). For instance, the above mentioned defintion does not offer substantial guidance to operationalise the concept.

Here we further open up the discussion on maladaptation and reconsider the conceptual boundaries of the concept, and assess to what extent it can be used to analyse negative effects of adaptation policies and measures. Based on a review of the maladaptation literature, we propose to add to the literature and deepen the exisitng definitions by a typology and discuss key issues which need to be taken into account when applying the concept in adaptation research.

\section{Defining boundaries of maladaptation: a typology}

With regards to maladaptation, the IPCC states that '[T]he adaptation literature is replete with advice to avoid maladaptation, but it is less clear precisely what is included as "maladaptation" (Noble et al. 2014:28). These difficulties stem from a number of sources. Granberg and Glover, for example, argue that "...there are neither widely accepted criteria nor yardsticks that have been developed to identify maladaptation" (2013:4). Furthermore, in addition to the varying local circumstances and the passage of time, the authors argue that identifying maladaptation is also plagued by the problem of subjective judgement.

A typology is a way of classifying and organising different phenomena into different types in scientific research (Ziemski 1975). In order to operationalise the concept of maladaptation, we focused on the definition with the aim of further specifiying what the dynamic feedback loops related to maladaptation are. This is what the widely used definition by Barnett and O'Neill calls the impacts adversely affect other systems, sectors or social groups (Barnett and O’Neill 2010). Our interest in particular is to tease out how these feedbacks can be conceptualised and what kinds of decisions need to be made in order to ensure conceptual and methodological soundness.

In order to do this, we conducted a literature review ${ }^{1}$ in order to search the latest empirical examples of maladaptation in the published literature. We used the latest peer reviewed research as the basis of our conceptual work because this enables us to compile and structure practical examples of maladaptation presented to date. After identifying the sample of literature, we constructed categories with special attention on feedbacks in the empirical examples and arrived a three general categories that could be identified. Hence, we deduce that three types of maladaptation can be identified: 1) rebounding vulnerability 2 ) shifting vulnerability and 3 ) eroding sustainable development (table 1 ).

\footnotetext{
${ }^{1}$ Literature review: search in Scopus for "maladaptation AND Climate Change" resulted in 66 articles. 22 of these articles were found relevant for the analysis based on initial assessment of keywords search. These were complemented with papers about maladaptation cited in IPCC (WGII, AR5, chapter 14) and within the found articles. In total 31 papers were analyzed in depth.
} 
(Table 1. HERE)

Rebounding vulnerability is a simple connection implying an adaptation action that increases current or future climate change vulnerability of the implementing actor (or the targeted actor(s) if implemented by e.g. a local government). The actor(s) can be affected in three different ways; through increasing exposure or sensitivity or by decreasing the actors' adaptive capacity. Shifting vulnerability increases current or future vulnerability for one or several external actors. The external actors' vulnerability can be affected through increased exposure or sensitivity, or by decreased adaptive capacity. Eroding sustainable development is an outcome of an adaptation action that increases GHG emissions, negatively impacts environmental conditions and/or social and economic values. These side effects are presented as negative in general without singling out affected actors, creating common pool problems.

The above typology can be applied to sketch out the boundaries of the maladaptation concept. We fully acknowledge that our sample of literature is not all encompassing and it is possible that we have missed out relevant literature. As notable in Table 1, the linkages between an adaptation action and the maladaptive outcome highlights negative effects on two scales: A local scale, where the implementing/targeted actor(s) or an identified external actor are directly affected by the action; A global scale, where the common pool (such as the atmosphere, water or the economy) is affected, which leads to indirect effects for all or several actors (figure 1).

(FIGURE 1. HERE)

\section{Applying the maladaptation concept - aspects to consider}

The application of this typology as a framework requires specifying the type, aim and target audience of an adaptation action, as well as the time scale at which the outcomes are measured.

\subsection{Defining maladaptation: conceptual point of departure}


When understanding maladaptation, it is crucial to consider the definition of adaptation, given the reciprocity of the two concepts. The IPCC's First Assessment Report (FAR) defines adaptation as a "process of adjustment to actual or expected climate and its effects. In human systems, adaptation seeks to moderate harm or exploit beneficial opportunities. In natural systems, human intervention may facilitate adjustment to expected climate and its effects" (FAR, glossary).

The Fourth Assessment Report (AR4) clarified the intent behind this adjustment (planned vs. autonomous). Planned adaptation is "the result of a deliberate policy decision, based on an awareness that conditions have changed or are about to change and that action is required to return to, maintain, or achieve a desired state" (AR4, glossary). The Fifth Assessment Report (AR5) further defined autonomous adaptation to be "in response to experienced climate and its effects, without planning explicitly or consciously focused on addressing climate change" and it is also referred to as “spontaneous adaptation”, (AR5, glossary).

This recognition of the intention behind the adaptation action is important for the reconceptualization of maladaptation. In order to operationalise maladaptation, we argue that autonomous adaptation should be excluded from this. When autonomous, the action is not intended for explicitly managing climate change effects, yet resulting in adaptation as by-product. If the negative outcomes of an autonomous adaptation were to be considered maladaptive, then, for instance, all outcomes of any policy decision that increase vulnerability or erode sustainable development could be considered maladaptive. Thus, we argue that (for the concept to be relevant and applicable for analysing policy outcomes) maladaptation should be defined as:

a result of an intentional adaptation policy or measure leading to negative outcome(s) for the targeted or other actors. A negative outcome of an autonomous adaptive action should not be defined as a maladaptive outcome since the intention of the policy or measure was not to adapt in the first place.

We have also chosen to not include so-called avoidant adaptation actions (e.g. Le Dang et al. 2013, Niemeyer et al. 2005) that are built on perceptions such as denial of a threat, wishful thinking and fatalism (Grothmann and Patt, 2005:203) as part of the reconceptualisation. If maladaptation is used to denote the non-action on adaptation, all action that is considered to be non-adaptation would be maladaptation. Defined as everything but adaptation, maladaptation loses its usefulness as an analytical concept.

In the reviewed literature, maladaptation is often restricted to climate- and environment related outcomes. For example, Niemeyer et al. (2005:1443) define maladaptation as “...human response [that] actively undermines the capacity of society to cope with climate change or further contributes to the problem". Hence, the key in identifying maladaptation is to understand the feedbacks from the 
adaptation action to climate change vulnerability, but also to related natural or human systems such as water and economic systems.

Consequently, it is important to distinguish between maladaptation and failed or unsuccessful policy implementation. The outcome of an adaptation action is not necessarily maladaptive, it might just be a failed policy, which does not reduce vulnerability to climate change impacts. However, if the action increases vulnerability, negatively affects actors' or organisations' ability to deal with climate impacts or their efforts to implement sustainable development goals (economic, environmental or social), the action can be considered to be maladaptive.

\subsection{Scales of maladaptation: spatial and temporal aspects}

Timescales are important when analysing adaptation actions since adaptation outcomes span across timescales. Specific adaptive actions might have a short-term positive impact, while resulting in negative outcomes in the long-term (e.g. Andersson-Sköld et al. 2015, Mycoo 2014, Brooks et al. 2010). In the AR5, the temporal aspect is included in the definition of maladaptation: "a cause of increasing concern to adaptation planners, where intervention in one location or sector could increase the vulnerability of another location or sector, or increase the vulnerability of the target group to future climate change" (AR5, glossary).

With regards to the spatial scale, a positive outcome of an adaptive action on a local scale could simultaneously imply negative impacts on a regional or a global scale. The identification of maladaptive actions thus requires a broad systems perspective (see Richards and Howden 2012), as well as a reflexive approach when identifying interdependencies and relationships between actors, sectors and goals. As McEvoy and Wilder (2012:355) argue - "one group's adaptation may be another group's hazard". Thus, through the recognition of scales, one can set boundaries in identifying maladaptation.

After setting the boundaries of analysis, the question arises at which point an adaptation action actually can be identified as maladaptation? At what threshold does an action aimed to respond to climate change result in negative outcomes? What criteria should be used to evaluate whether these consequences are determined as negative - for whom, where and when?

\section{Conclusions}

Based on our analysis of the conceptual boundaries, we argue that maladaptation should be defined as a result of an intentional adaptation policy or measure leading to negative outcome(s) for the targeted 
or other actors. We note that in order for maladaptation to be a useful concept, the recognition of adaptation as an intentional action and the importance of setting clear spatial and temporal boundaries in analysing negative outcomes of adaptation policy is key. The proposed typology of maladaptation highlighting three distinguished types of maladaptive outcomes - rebounding vulnerability, shifting vulnerability and eroding sustainable development - can be used as a starting point for such analyses.

We argue that the potential for maladaptation as a concept is twofold. First, it can be used to open up the debate on the effectiveness, equitableness and appropriateness of adaptation policies and measures and the acknowledgment of their diverse effects. Furthermore, if the boundaries of the analysis are set, it can, for instance, be used to identify potential maladaptive actions in case studies. Second, as a consequence, the concept can serve to further assess the coherence of climate and sustainable development policy, in particular to understand the effects of adaptation policy on mitigation or other environmental policy to ensure that adaptation actions do not increase pollution, such as GHG emissions, in the long term. The potential of an adaptation action to directly undermine the ability to adapt or to create more need for mitigation has to be conceptually clarified and operationalised in research.

This clarification opens up for analyses of maladaptive outcomes empirically. In doing so, it is important to assess how the various aspects of vulnerability are affected. A departure here could be Barnett and O'Neill's (2013) recognition that some adaptive actions may generate bigger risks for maladaptation than others. According to the authors, adaptation actions that reduce exposure carry the biggest risk for maladaptation, those decreasing sensitivity a moderate risk, whilst building adaptive capacity is considered to be least likely to lead to maladaptation.

We also acknowledge the limits of the previous use of the maladaptation concept, in terms of the multitude of definitions and lack of clear delimitations. The outcomes of policy actions will always be uncertain and unpredictable to a degree, making their assessment a challenge. Even successful policy outcomes will likely have negative effects in varying degrees for some. We propose, however, that for adaptation policy and measures, the concept of maladaptation can be used to identify some of these. By systematically setting system boundaries and developing criteria for assessment, the maladaptation concept could be opened up for wider and more thorough empirical analyses of these outcomes.

\section{References}

Adger W.N., Brown K., Nelson D.R., Berkes F., Eakin H., Folke C., Galvin K., Goulden M., Gunderson L., O’Brien K., Ruitenbeek J. and Tompkins E.L., 2010. Resilience implications of responses to climate change. Wileys Climate Change, 2(5), 757-766. DOI: 10.1002/wcc.133 
Adger, W. Neil, Nigel W. Arnell, and Emma L. Tompkins, 2005. Successful adaptation to climate change across scales. Global Environmental Change 15(2): 77-86.

Adger, W. N., Dessai, S., Goulden, M., Hulme, M., Lorenzoni, I., Nelson, D. R., ... \& Wreford, A. (2009). Are there social limits to adaptation to climate change?. Climatic Change, 93(3-4), 335-354.

Adger W.N., Huq S., Brown K., Conway D. and Hulme M. 2003. Adaptation to climate change in the developing world. Progress in Development Studies, 3(3), 179-195. DOI: $10.1191 / 1464993403$ ps060oa

Adger, W.N., S. Agrawala, M.M.Q. Mirza, C. Conde, K. O'Brien, J. Pulhin, R. Pulwarty, B. Smit and K. Takahashi, 2007: Assessment of adaptation practices, options, constraints and capacity. Climate Change 2007: Impacts, Adaptation and Vulnerability. Contribution of Working Group II to the Fourth Assessment Report of the Intergovernmental Panel on Climate Change, M.L. Parry, O.F. Canziani, J.P. Palutikof, P.J. van der Linden and C.E. Hanson, Eds., Cambridge University Press, UK, 717-743

Andersson-Sköld Y., Thorsson S., Rayner D., Lindberg F., Janhäll S., Jonsson A.C., Moback U., Bergman R. and Granberg M. 2015. An integrated method for assessing climate-related risks and adaptation alternatives in urban areas. Climate Risk Management, 7, 31-50. DOI:10.1016/j.crm.2015.01.003

Barnett J. and O'Neill S.J. 2010. Maladaptation. Global Environmental Change, 20(2), 211-213. DOI:10.1016/j.gloenvcha.2009.11.004

Barnett J. and O’Neill S.J. 2012. Islands, resettlement and adaptation. Nature Climate Change, 2, 810. DOI:10.1038/nclimate1334

Barnett J. and O'Neill S.J. Minimising the risk of maladaptation: A framework for analysis. In: Palutikof J., Boulter S.L., Ash A.J., Stafford Smith M., Parry M., Waschka M. and Guitart D. (Eds). 2013. Climate adaptation futures. John Wiley and Sons, UK. pp. 87-93

Beilin R., Sysak T and Hill S. 2011. Farmers and perverse outcomes: The quest for food and energy security, emissions reduction and climate adaptation. Global Environmental Change, 22(2), 463-471. DOI:10.1016/j.gloenvcha.2011.12.003

Bélanger D., Gosselin P., Valois P. and Abdous B. Use of residential wood heating in a context of climate change: a population survey in Québec (Canada). Public Health, 8, 184. DOI:10.1186/14712458-8-184

Benito-Garzón M., Ha-Duong M., Frascaria-Lacoste N. and Fernández-Manjarrés J. 2013. Habitat Restoration and Climate Change: Dealing with Climate Variability, Incomplete Data, and Management Decisions with Tree Translocations. Restoration Ecology, 21(5), 530-536. DOI: 10.1111/rec.12032 
Biesbroek G-R., Klostermann J.E.M., Termeer C.J.A.M. and Kabat P. 2013. On the nature of barriers to climate change adaptation. Regional Environmental Change, 13, 1119-1129. DOI: 10.1007/s10113013-0421-y

Biesbroek, G. R., Swart, R. J., Carter, T. R., Cowan, C., Henrichs, T., Mela, H., \& Rey, D. 2010. Europe adapts to climate change: comparing national adaptation strategies. Global Environmental Change, 20,3, 440-450.

Brooks N., Grist N. and Brown K. 2010. Development futures in the context of climate change: Challenging the present and learning from the past. Development Policy Review, 27(6), 741-765. DOI: 10.1111/j.1467-7679.2009.00468.x

Burton, I., Huq, S., Lim, B., Pilifosova, O., \& Schipper, E. L. 2002, From impacts assessment to adaptation priorities: the shaping of adaptation policy. Climate Policy, 2, 2-3, 145-159.

Eriksen, S.H. and Kelly P.M. 2007. Developing credible vulnerability indicators for climate adaptation policy assessment. Mitigation and Adaptation Strategies for Global Change, 12, 495-524. DOI: 10.1007/s11027-006-3460-6

Ford J.D., McDowell G., Shirley J., Pitre M., Siewierski R., Gough W., Duerden F., Pearce T., Adams P. and Statham S. 2013. The Dynamic Multiscale Nature of Climate Change Vulnerability: An Inuit Harvesting Example. Annals of the Association of American Geographers, 103(5), 1193-1211. DOI:10.1080/00045608.2013.776880

Ford, J. D., Berrang-Ford, L., \& Paterson, J. (2011). A systematic review of observed climate change adaptation in developed nations. Climatic Change, 106,2, 327-336.

Füssel, H. M. 2007a. Adaptation planning for climate change: concepts, assessment approaches, and key lessons. Sustainability Science, 2,2, 265-275.

Füssel, H. M. 2007b. Vulnerability: a generally applicable conceptual framework for climate change research. Global Environmental Change, 17, 2, 155-167.

Gallopín, G. C. 2006. Linkages between vulnerability, resilience, and adaptive capacity. Global environmental change, 16,3, 293-303.

Glaas E. 2014. A mapping of climate change risks and adaptation guidelines to house owners in Denmark, Norway and Sweden. Centre for Climate Science and Policy Research, Briefing No. 11, 2014. Linköping University, Sweden.

Granberg M. and Glover L. 2013. Adaptation and Maladaptation in Australian National Climate Change Policy. Journal of Environmental Policy and Planning. DOI:10.1080/1523908X.2013.823857 
Grothmann T. and Patt A. 2005. Adaptive capacity and human cognition: the process of individual adaptation to climate change. Global Environmental Change, 15(3), 199-213.

Hopkins D. 2014. The sustainability of climate change adaptation strategies in New Zealand's ski industry: a range of stakeholder perceptions. Journal of Sustainable Tourism, 22(1), 107-126. DOI: 10.1080/09669582.2013.804830

Kelly, P. M., \& Adger, W. N. 2000. Theory and practice in assessing vulnerability to climate change and facilitating adaptation. Climatic Change, 47,4, 325-352.

Klein R.J.T., Eriksen S.E.H., Næss L.O., Hammill A., Tanner, T.M., Robledo C. and O'Brien K.L. 2007. Portfolio screening to support the mainstreaming of adaptation to climate change into development assistance. Climatic Change, 84, 23-44. DOI: 10.1007/s10584-007-9268-x

Klein RJT. and Juhola S. 2014. A framework for Nordic actor-oriented climate adaptation research. Environmental Science \& Policy, 40, 101-115. DOI:10.1016/j.envsci.2014.01.011

Lamhauge N., Lanzi E., and Agrawala S. 2011. Monitoring and evaluation for adaptation: lessons from development co-operation agencies. OECD Environment Working Papers No. 38, OECD Publishing, Paris, 50 pp.

Le Dang, H., Li E., Bruwer J. and Nuberg i. 2013. Farmers' perceptions of climate variability and barriers to adaptation: lessons learned from an exploratory study in Vietnam. Mitigation and Adaptation Strategies for Global Change, 19(5), 531-548. DOI: 10.1007/s11027-012-9447-6

Macintosh A. 2013. Coastal climate hazards and urban planning: How planning responses can lead to maladaptation. Mitigation and Adaptation Strategies for Global Change, 18(7), 1035-1055. DOI: $10.1007 / \mathrm{s} 11027-012-9406-2$

McEvoy J. and Wilder M. 2012. Discourse and desalination: Potential impacts of proposed climate change adaptation interventions in the Arizona-Sonora border region. Global Environmental Change, 22(2), 353-363. DOI: 10.1016/j.gloenvcha.2011.11.001

Moser, S. C., \& Ekstrom, J. A. (2010). A framework to diagnose barriers to climate change adaptation. Proceedings of the National Academy of Sciences, 107(51), 22026-22031.

Mycoo M.A. 2014. Autonomous household responses and urban governance capacity building for climate change adaptation: Georgetown, Guyana. Urban Climate, 9, 134-154. DOI: 10.1016/j.uclim.2014.07.009

Niemeyer S., Petts J.B. and Hobson K. 2005. Rapid climate change and society: Assessing responses and thresholds. Risk Analysis, 25(6), 1443-1456. DOI: 10.1111/j.1539-6924.2005.00691.x 
Noble I.R., S. Huq, Y.A. Anokhin, J. Carmin, D. Goudou, F.P. Lansigan, B. Osman-Elasha and A. Villamizar, 2014: Adaptation needs and options. In: Climate Change 2014: Impacts, Adaptation, and Vulnerability. Part A: Global and Sectoral Aspects. Contribution of Working Group II to the Fifth Assessment Report of the Intergovernmental Panel on Climate Change [Field, C.B., V.R. Barros, D.J. Dokken, K.J. Mach, M.D. Mastrandrea, T.E. Bilir, M. Chatterjee, K.L. Ebi, Y.O. Estrada, R.C. Genova, B. Girma, E.S. Kissel, A.N. Levy, S. MacCracken, P.R. Mastrandrea, and L.L.White (eds.)]. Cambridge University Press, Cambridge, United Kingdom and New York, NY, USA, pp. 833-868

OECD. 2009. Integrating Climate Change Adaptation into Development Co-Operation: Policy Guidance. OECD, Paris, 193 pp.

Olmstead S.M. 2013. Climate change adaptation and water resource management: A review of the literature. Energy Economics. [http://dx.doi.org/10.1016/j.eneco.2013.09.005]

Pielke, R., Prins, G., Rayner, S., \& Sarewitz, D. 2007. Climate change 2007: Lifting the taboo on adaptation. Nature, 445, 7128, 597-598.

Pittock J. 2011. National climate change policies and sustainable water management: conflicts and synergies. Ecology and Society, 16(2): 25. http://www.ecologyandsociety.org/vol16/iss2/art25/

Quezada G., Grozev G., Seo S. and Wang C-H. 2014. The challenge of adapting centralised electricity systems: peak demand and maladaptation in South East Queensland, Australia. Regional Environmental Change, 14(2), 463-473. DOI: 10.1007/s10113-013-0480-0

Quinn C.H., Ziervogel G., Taylor A., Takama T. and Thomalla F. 2011. Coping with Multiple Stresses in Rural South Africa. Ecology and Society, 16(3), 2. DOI: 10.5751/ES-04216-160302

Richards L. and Howden S.M. 2012. Transformational adaptation: Agriculture and climate change. Crop and Pasture Science, 63(3), 240-250. DOI: 10.1071/CP11172

Smit, B., \& Wandel, J. 2006. Adaptation, adaptive capacity and vulnerability. Global environmental change, 16,3, 282-292.

Smit, B., Burton, I., Klein, R. J., \& Wandel, J. (2000). An anatomy of adaptation to climate change and variability. Climatic Change, 45(1), 223-251.

Smit, B. (Ed.), 1993. Adaptation to Climatic Variability and Change: Report of the Task Force on Climate Adaptation. Canadian Climate Program, University of Guelph, Ontario.

Sovacool B., Linnér B-O and Goodsite M. Fc. A political economy view on climate change adaptation. Nature Climate Change, DOI: 10.1038/nclimate2665

Thomsen D.C., Smith T.F. and Keys N. 2012. Adaptation or manipulation? Unpacking climate change response strategies. Ecology and Society, 17(3), 20. DOI: 10.5751/ES-04953-170320 
UNFCCC. 2007. Investment and Financial Flows to Address Climate Change. UNFCCC Secretariat, Bonn, Germany, 111 pp.

Ziemski, Stefan. "The typology of scientific research." Zeitschrift für allgemeine Wissenschaftstheorie 6.2 (1975): 276-291. 